Journal of Engineering and Applied Sciences 14 (15): 5220-5226, 2019

ISSN: 1816-949X

(C) Medwell Journals, 2019

\title{
Experimental and Numerical Investigation of Temperature Distribution in Twisted Tape
}

\author{
Ali Adel Battawi, Sohaib Khlil Ibrahim and Abdulwahab Hassan Khuder \\ Department of Applied Mechanics Engineering, Technical College Baghdad, \\ Middle Technical University, Baghdad, Iraq \\ 07801607235@yahoo.com,+9647801607235,Sohaib_khlil@yahoo.com,+9647717538584 \\ akhuder4@gmail.com,+9647709688982
}

\begin{abstract}
Recently, it was important to improve heat transfer performance of heat exchanger because they were considered general equipment. Heat exchangers have many applications such as power production units, home appliances, manufacturing companies and transportations. The current study presents results obtained from experimental investigations the enhancement the heat transfer by a horizontal tube through means changing twisted tape that insert in pipe tube with water as a working fluid. The thermo hydraulic performance depends on several factors such as configurations of geometry insert. An experimental and numerical investigation via. ANSYS 11.0/ Flotran is carried out with twisted tapes under different shape configuration of tapes. Sixteen cases are investigated in this study, firstly, the tube without holes in the tape is tested with different hole diameters $(4,7.5$ and $10.5 \mathrm{~mm})$ each one has 1-4 twists. It can be concluded that the number of twisted tapes was directly proportional to the velocity and inversely with temperature. The hole diameters in the twisted tape have an effect on the distribution of temperature and velocity. Good agreement is evident between experimental and numerical results with discrepancy $4 \%$. It was found that the tape with two twists superior in heat transfer about $(31 \%)$ as compared with another twisted tapes.
\end{abstract}

Key words: Twisted tape, heat transfer, ANSYS/Flotran, temperature distribution, velocity, experimental

\section{INTRODUCTION}

The operation of improving the behavior of a heat transfer system in terms of increase the coefficient of heat transfer was named as enhancement of heat transfer (Patil and Babu, 2011). Consequently, leads to minimize cost and size of the heat exchanger. There are three methods are adopted to improve heat transfer. The first method is active method, in this method some external power inputs are required for improving the thermal behavior of the heat exchanger; fluid vibration, mechanical aids, electrostatic fields, surface vibration, jet impingement and suction are examples of this method. The second is passive method, in this method some obstacles are inserted into the flow inside the tube of heat exchangers in order to create disturbed and turbulence (Patil and Babu, 2011). The turbulence that made in the tube increases the pressure drop and reducing the wall temperature and consequently, heat transfer coefficient was increased (Kang et al., 2013). This method is recommended more because it does not require any type of external power. This method is also, a sample, cheap and can be easily implemented Savekar et al. (2015).
Extended surfaces, rough surfaces, additives for liquid and gases, helical screw tape and twisted tape inserts are examples of this method. Lastly, compound method in this method two or more methods are combined at the same time to improvement in thermal performance of heat exchanger (Mulla et al., 2014). Many applications like cooling and heating in evaporators, thermal power plants, air-conditioning equipment and refrigerators, process industries, automobiles and radiators for space vehicles have used these methods (passive, active or mixing between the both methods).

This research deals with twisted tapes. In general, twisted tapes were put in the flow passage to enhance the rate of heat transfer. As a result, the hydraulic diameter of the flow passage is reduced. The enhancement in the heat transfer that results from the inserted twisted tape is mostly due to the flow blockage, partitioning of the flow and secondary flow (Yadav, 2009). The pressure drop and flow velocity are increased because flow blockage. The increment in the pressure drop leads to increase viscous due to the reduction free flow area. In addition, in some cases the increase in the flow velocity caused a serious secondary flow. The advantage of secondary flow is to

Corresponding Author: Sohaib Khlil Ibrahim, Department of Applied Mechanics Engineering, Technical College Baghdad, Middle Technical University, Baghdad, Iraq, Sohaib_khlil@yahoo.com, +9647717538584 
provide a good thermal contact between the surface and the fluid. The resulting of this max improves the temperature gradient which finely enhance the heat transfer coefficient (Patil and Babu, 2011; Savekar et al., 2015).

Significant investigations on circular tubes containing twisted tape inserts were found in the present study. Saha et al. (1989), study the performance of pressure drop and heat transfer of laminar flow in a circular type tube placed with fixed distance twisted tape inserts connected with a rod. The finding of the study was that the performance of thermo hydraulic is better in the case of twisted tape inserts connected with rod, wider width of tape elements and thinner connecting rod. Manglik and Bergles (1993), investigated the impact of twisted tape in laminar flow. It was found that the main reasons for improving the heat transfer coefficient are higher flow velocities and reduction in hydraulic diameter which is resulted by twisted tape. Mogaji et al. (2013) were investigated the experiments conducted to estimate the effect of twisted tape insert on the increase of the pressure drop and heat transfer coefficient during flow boiling of R134a into horizontal tubes. It was observed that when using twisted tape, pressure drop and coefficient of heat transfer were enhancements up to 133 and $36 \%$, respectively. Sheeba et al., examined how different twisted ratios affect the heater system performance of solar water, adjust with spiral twisted tape. The outcomes of the study showed that the heat transfer was enhanced in twisted tape collector were greater than the plain tube with lowest twisted ratio and progressively reduces with the increase in twist ratio. Thermal behavior of twisted tape collector was found to be increased with the increase in solar intensity (Nagayach et al., 2012).

Oni (2015) conduct a comprehensive comparative study of fluid and heat transfer of water in tube caused by twisted tape inserts with different shape. In this study the attention was given to the thermo hydraulic behavior of transitional, turbulent and laminar flows of water via. various tube designs. The study was carried out by using simulation. The results of this study revealed that triangular cut twisted tape offers better heat transfer enhancement than other twisted. Hassan et al. (2015) enhanced the activity of the flat plate solar collector by adding twisted tapes with different ratios. The research was carried out by connecting three collectors with various flow rates. The greater heat transfer rate was found at a twisted ratio 3 .

Shakir et al. (2016) accomplished a numerical investigation of the effect of axial pitch to fin height ratios for single phase flow behavior in thirty-six tubes internally finned to enhance force convection of heat transfer beside reduction of friction factor by using the ANSYS program. Rakate et al. (2016) carried out an experimental investigation on a plain tube with twisted tapes and without twisted tapes under different heat flux and different mass flow rates. Different twisted ratios were taken into account, it was found that twist tape with 3.64 give an enhancement in heat transfer as compared to other twisted ratios and the plain tube. In this research an experimental and numerical investigation via. ANSYS 11.0/Flotran is carried out with twisted tapes under different shape configuration of tapes.

\section{MATERIALS AND METHODS}

Experimental design: The representation of the schematic diagram of experimental design is shown in Fig. 1a, along with its photograph shown in Fig. 1b. The experimental design composed of a test tube, hot fluid tank, pump, five thermocouples and bypass valve.

The tested tube is a straight pipe heat exchanger made from copper and has an inner diameter of $22 \mathrm{~mm}$ and the length of the tube is $1 \mathrm{~m}$. Twisted tapes are made from aluminum strips with $1.00 \mathrm{~mm}$ thick and $1 \mathrm{~m}$ total length. The tapes are twisted on a lathe using manual rotations of the chuck. The width of the tape is $2 \mathrm{~mm}$ less from inside diameter of the tube. The hot fluid (water) is pumped inside the tube using a pump and controlled bypass valve. During the experiments, the flow rate of hot fluid in inner tube is kept constant. The five k-type thermocouples are used to measure the temperatures of the fluid, located in the tube as shown in Fig. 1. The rmocouple needles are readings manually through the digital recorder. The thermocouples are calibrated $\left( \pm 0.1 \%{ }^{\circ} \mathrm{C}\right)$ before using in the test tube section. The fluid which take place in a closed loop, enter the test tube to maintain the inside temperature constant. Then the twisted tapes are inserted into the tube with different twisted and different holes.

Cases study: Sixteen cases are investigated in this study, firstly, the tube without holes in the tape is tested, then with different hole diameters $(4,7.5$ and $10.5 \mathrm{~mm})$ each with 1-4 twists. As shown in Fig. 2.

ANSYS simulation: Simulation methods based on computational fluid dynamics are investigated. The numerical investigation in this research is dealing with fluid flow and heat transfer thermo hydraulic behavior of water in the tubes. The governing equations with the standard model are two-equation turbulence model is proposed as well as the modeling equations are simulated by Foltran in ANSYS 11. As the working fluid (water) is 


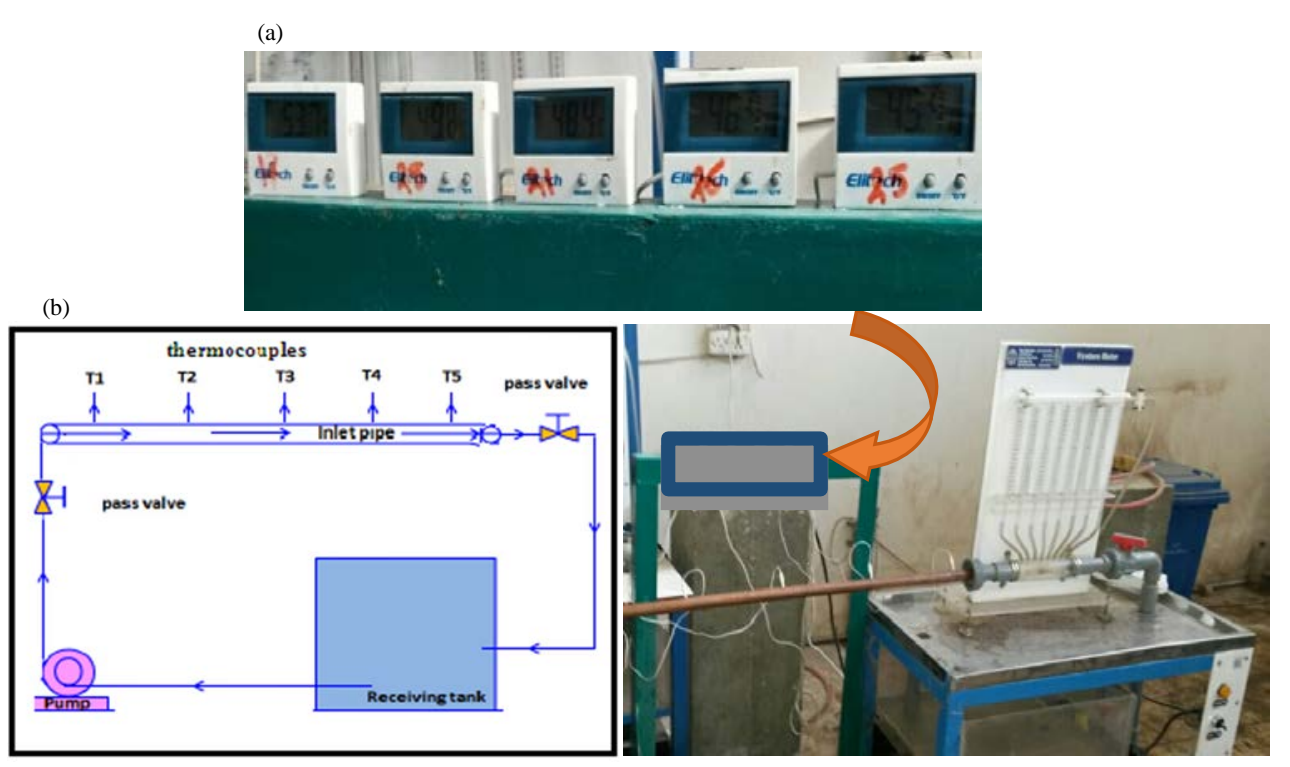

Fig. 1: Experimental setup: a) Schematic diagram and b) Assembly device utilized to measure temperature

(a)

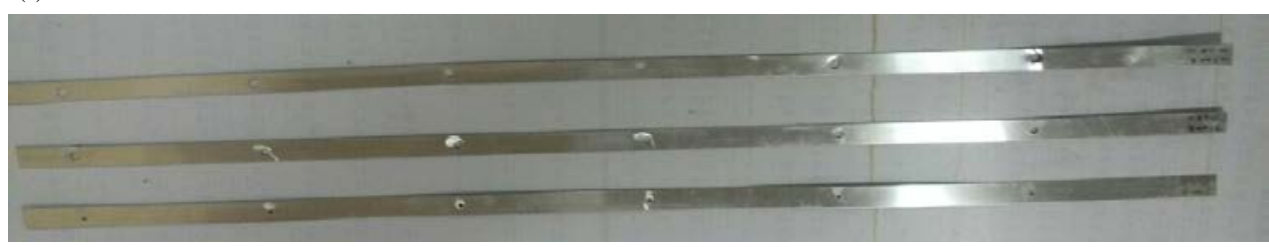

(b)

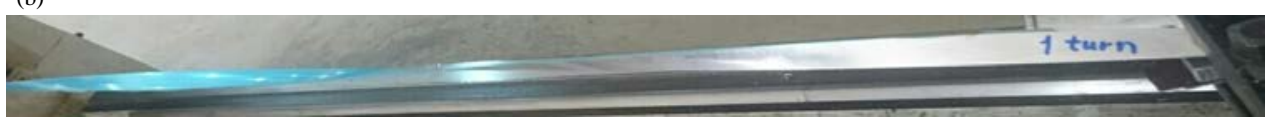

(c)

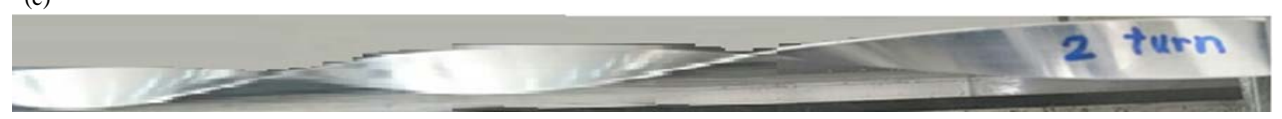

(d)

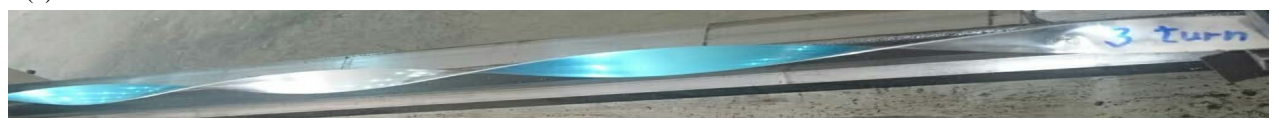

(e)

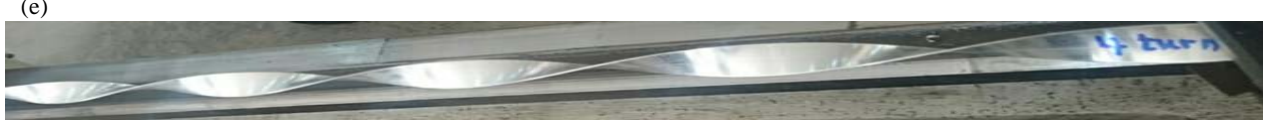

Fig. 2: Different type of tapes with 1-4 twists: a) Hole diameter (4, 7.5 and $10.5 \mathrm{~mm})$; b) 1 twist; c) 2 twist; d) 3 twist and e) 4 twist

considered to be Newtonian, the Navier-Stokes equation are used to represent the flow of the fluid. As a result, the heat transfer and fluid flow that are considered in this study ruled by the Navier-Stokes and energy transfer equation. The working fluid is assumed to be incompressible. A three dimensional physical model of the twist tape is produced by ANSYS 11.0 /Flotran Software. This model shown in Fig. 3 is designed with reference to the actual physical utilized in experimental studies. The meshing is done in ANSYS/Flotran. The volume mesh is carried out using element Fluid1 42. 


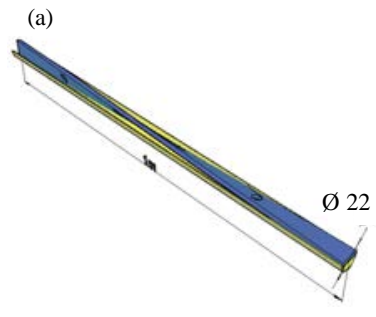

(d) (b)

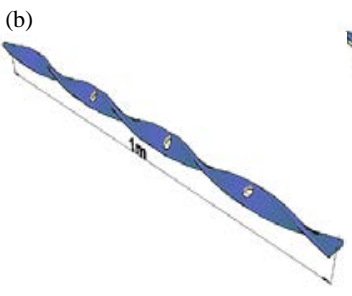

(c)

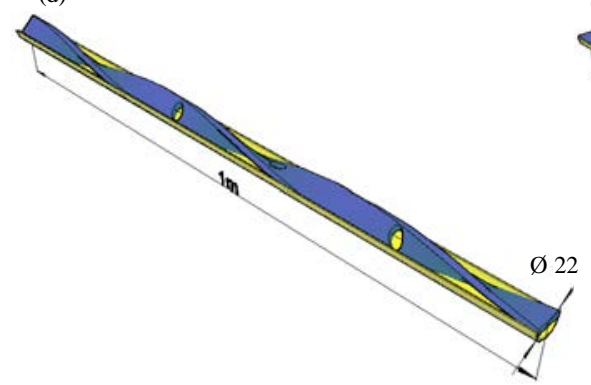

(e)

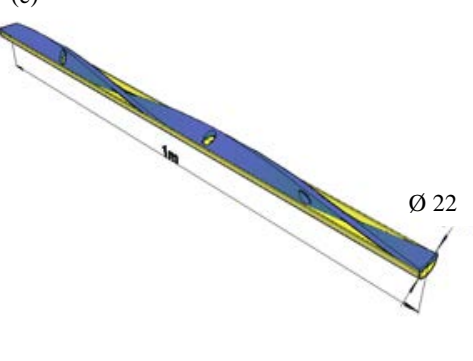

Fig. 3: a-e) Three dimensional model of the twisted tape

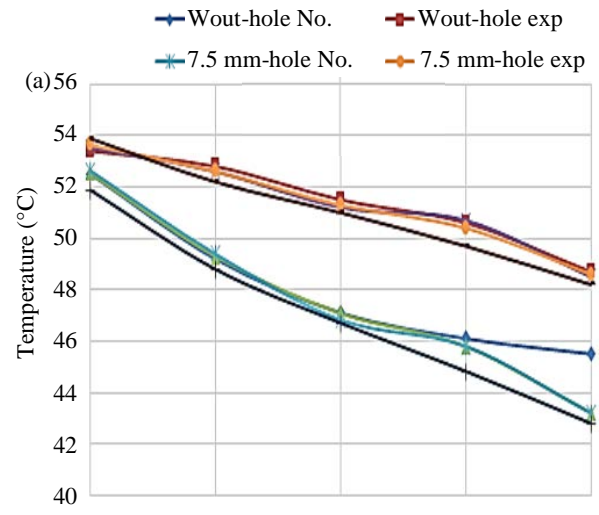

$$
\begin{array}{ll}
\text {-4 mm-hole No. } & \quad 4 \text { mm-hole exp } \\
+10.5 \text { mm-hole No. } & \quad-10.5 \text { mm-hole exp }
\end{array}
$$
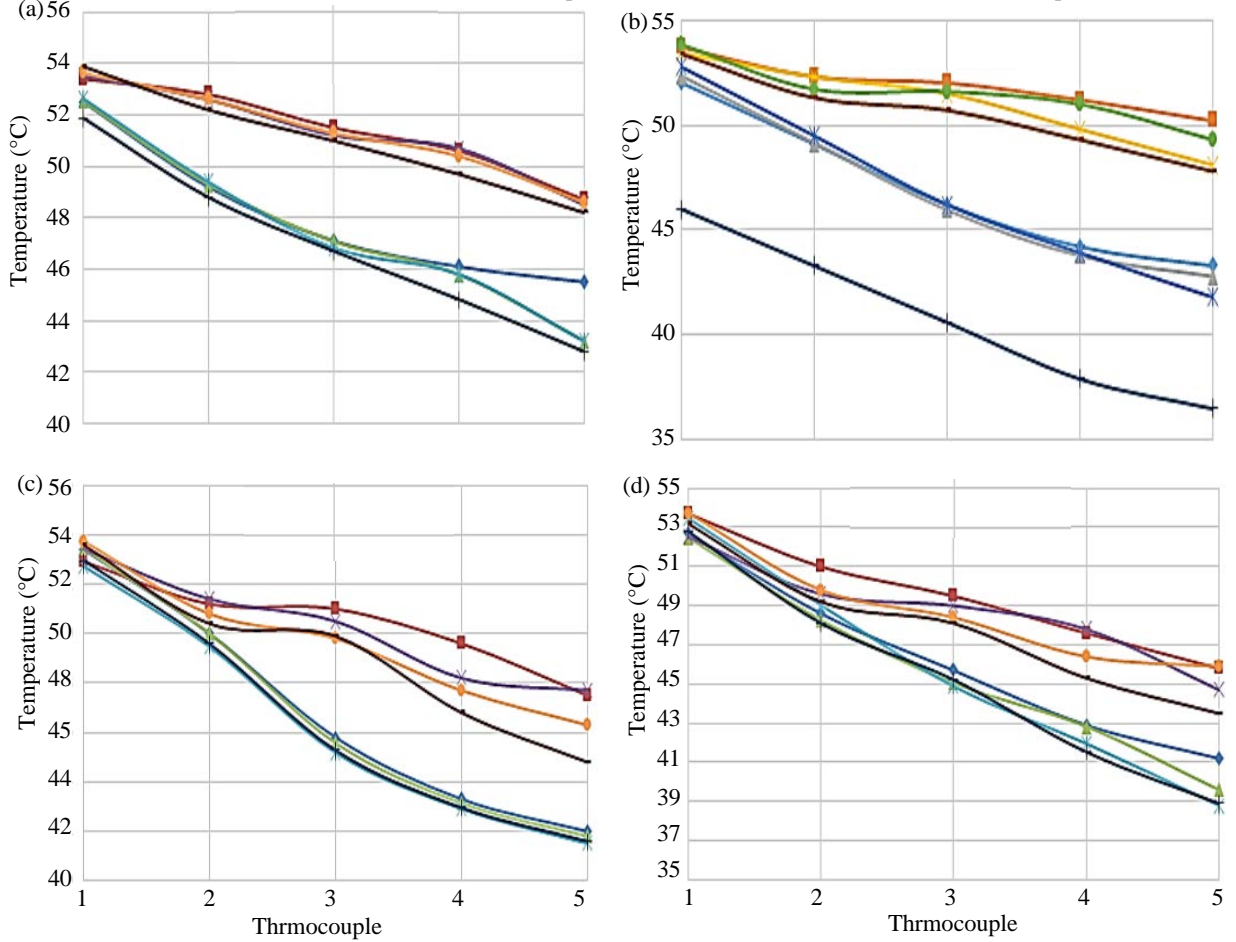

Fig. 4: Experimental and numerical comparison in temperature distribution: a) 1 twist; b) 2 twist; c) 3 twist and d) 4 twist

\section{RESULTS AND DISCUSSION}

In this study the temperature distribution and velocity is measured to investigate the effect of the twisted tape. Figure 4 explained the comparison between experimental and numerical results. It temperature explained that good agreement is evident between them with discrepancy $(4 \%)$. Table 1 illustrated the distribution of temperature in ANSYS 11.0/Flotran with different cases of twisted taped. 
J. Eng. Applied Sci., 14 (15): 5220-5226, 2019

Table 1: Temperature distribution for different twist turn and holes in different locations

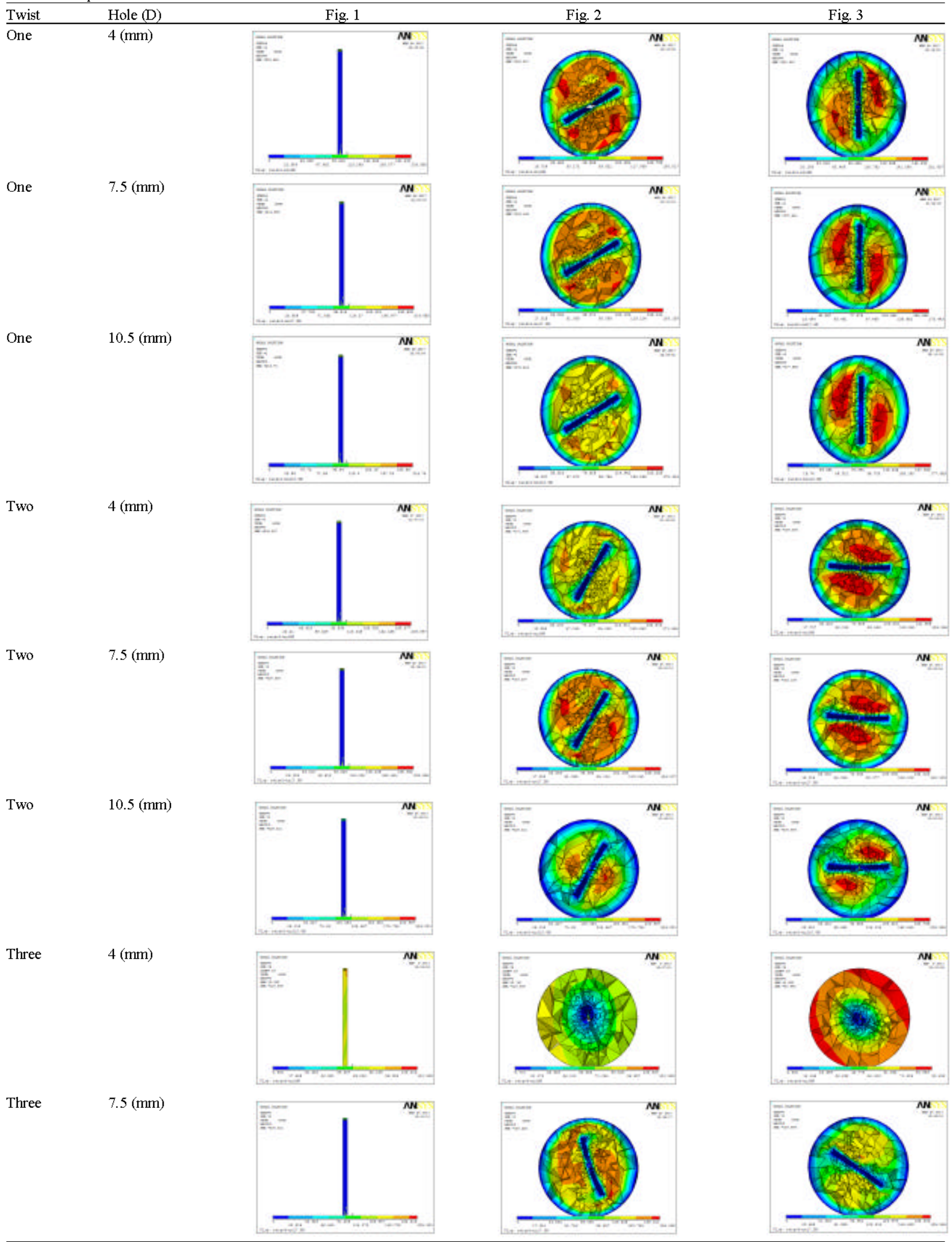


Table 1: Continue

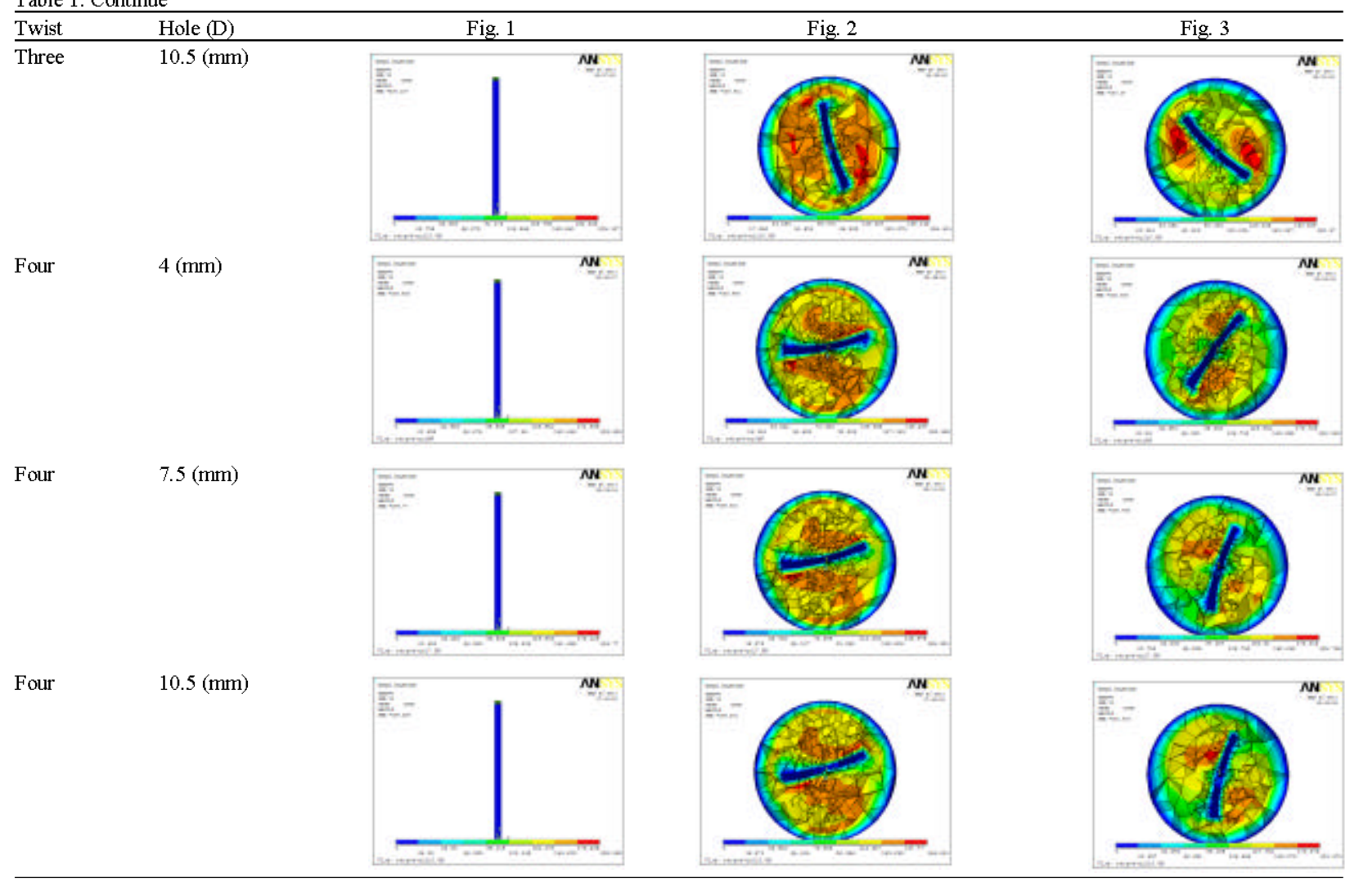
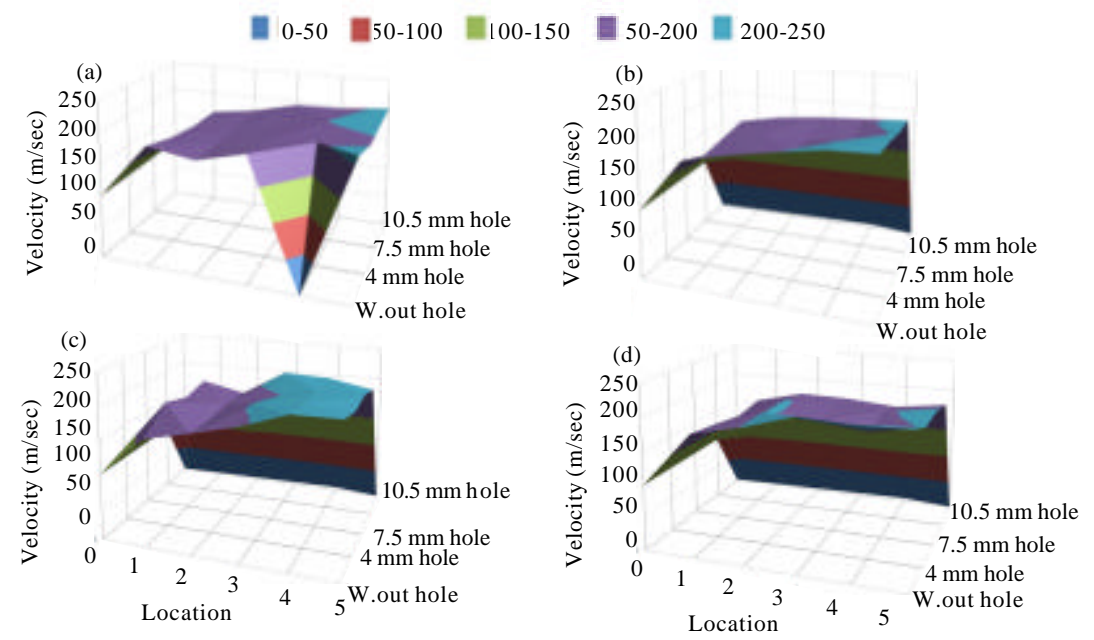

Fig. 5: Velocity distribution in three-dimensional view: a) 1 twist; b) 2 twist; c) 3 twist and d) 4 twist

Figure 4 an 5 displays the comparison of experimental and numerical results of temperature at five locations over the length of the tube with different twist tape and different hole diameter. The numerical results are aligned with the experimental results, also it was observed tape has 2 twist and $(10.5 \mathrm{~mm})$ hole diameter provides a higher decrease in temperature about $(31 \%)$ as compared with another twisted tapes $(20,21$ and $27 \%)$ for 1-4 twists, respectively. Hence, increasing of twisted number will get turbulent behavior of flow, thus, due to low decrease in temperature. Velocity distribution is presented in three dimensional plotting in Fig. 5, obviously, tape with one and two twists have uniform velocity distribution due to the laminar behavior of flow while for 3 and 4 twists 
fluctuating along the tube length was observed due to the formation of vortices around the tape which led to turbulent behavior of flow.

\section{CONCLUSION}

Tape inserts in tubes are a technique employed in industrial practices. An experimental and numerical study was achieved of the heat transfer in tube with different twisted tapes and different hole diameter. It can be concluded that the number of twisted tapes is directly proportional to the velocity and inversely to temperature. The hole diameter in the twisted tape has a simple effect on the distribution of temperature and velocity. Also, it was observed the tape has 2 twist and $(10.5 \mathrm{~mm})$ hole diameter provide a higher decrease in temperature about $(31 \%)$ as compare with another twisted tapes $(20,21$ and $27 \%$ ) for 1,3 and 4 twists, respectively. It was found that tape with 2 twist gave an improved in heat transfer as compared with another twisted tapes. Good agreements between numerical and experimental results are found.

\section{ACKNOWLEDGEMENT}

I would like to express my very great appreciation to Dr. Hani Aziz Amean for his valuable and constructive suggestions during the planning and development of this research work. His willingness to give his time so generously has been very much appreciated.

\section{REFERENCES}

Hassan, J.M., Q.J. Abdul-Ghafour and M.F. Mohammed, 2015. Influences of the twisted strips insertion on the performance of flat plate water solar collector. Al Khwarizmi Eng. J., 11: 37-47.

Kang, H.K., S.W. Ahn, M.S. Lee and D.H. Lee, 2013. Prediction of fluid flow and heat transfer through square duct with twisted tape insert and interrupted rib. Trans. Canad. Soc. Mech. Eng., 37: 917-925.

Manglik, R.M. and A.E. Bergles, 1993. Heat transfer and pressure drop correlations for twisted-tape inserts in isothermal tubes: Part II-Transition and turbulent flows. J. Heat Trans., 115: 890-896.
Mogaji, T.S., F.T. Kanizawa, E.P. Bandarra Filho and G. Ribatski, 2013. Experimental study of the effect of twisted-tape inserts on flow boiling heat transfer enhancement and pressure drop penalty. Proceedings of the ECI 8th International Conference on Boiling and Condensation Heat Transfer, June 3-7, 2013, Lausanne, Switzerland, pp: 1-11.

Mulla, A.M., U. Jangamashetti and K. Kiran, 2014. Experimental study on heat transfer and friction factor characteristics in laminar flow through tubes of shell and tube heat exchanger fitted with twisted tapes with baffles. Intl. J. Res. Eng. Technol., 3: 426-431.

Nagayach, N.K., B.A. Alka and P. Vishwavidyalaya, 2012. Review of heat transfer augmentation in circular and non-circular tube. Intl. J. Eng. Res. Appl., 2: 796-802.

Oni, T.O., 2015. Numerical investigation of heat transfer and fluid flow in tubes induced with twisted tape inserts. Ph.D Thesis, University of Glasgow, Glasgow, Scotland.

Patil, S.V. and P.V. Babu, 2011. Heat transfer augmentation in a circular tube and squareduct fitted with swirl flow generators: A review. Intl. J. Chem. Eng. Appl., 2: 326-331.

Rakate, Y.B., K. Bhavsar and S.S. Umale, 2016. Experimental and numerical analysis of heat transfer augmentation through a Pipe using twisted tapes. Intl. J. Innovative Res. Sci. Technol., 2: 65-71.

Saha, S.K., U.N. Gaitonde and A.W. Date, 1989. Heat transfer and pressure drop characteristics of laminar flow in a circular tube fitted with regularly spaced twisted-tape elements. Exp. Therm. Fluid Sci., 2: 310-322.

Savekar, A., D. Jangid, M. Gurjar, V. Patil and C.M. Sewatkar, 2015. Analysis of heat transfer in pipe with twisted tape inserts. Proceedings of the 2nd International Conference on Fluid Flow, Heat and Mass Transfer, April 30-May 1, 2015, Ottawa, Canada, pp: 143-1-143-8.

Shakir, A., A. Ali and N. Mohammed, 2016. Numerical investigation for enhancement of heat transfer in internally finned tubes using ANSYS CFX program. Basrah J. Eng. Sci., 16: 89-99.

Yadav, A.S., 2009. Effect of half length twisted-tape turbulators on heat transfer and pressure drop characteristics inside a double pipe U-bend heat exchanger. Jordan J. Mech. Ind. Eng., 3: 17-22. 